\title{
Response of Nitrous Oxide Flux to Addition of Anecic Earthworms to an Agricultural Field
}

\author{
José A. Amador, Edward J. Avizinis \\ Laboratory of Soil Ecology and Microbiology, 024 Coastal Institute, University of Rhode Island, Kingston, USA. \\ Email: jamador@uri.edu
}

Received January $29^{\text {th }}, 2013$; revised March $4^{\text {th }}, 2013$; accepted March $12^{\text {th }}, 2013$

Copyright (C) 2013 José A. Amador, Edward J. Avizinis. This is an open access article distributed under the Creative Commons Attribution License, which permits unrestricted use, distribution, and reproduction in any medium, provided the original work is properly cited.

\begin{abstract}
The burrowing and feeding activities of earthworms may have a strong effect on the flux of $\mathrm{N}_{2} \mathrm{O}$ from agricultural soils. As such, shifts to agricultural management practices that increase the number of earthworms require an understanding of the role of earthworms in $\mathrm{N}_{2} \mathrm{O}$ dynamics. We conducted a field experiment to examine the effects of addition of anecic earthworms (Lumbricus terrestris) on $\mathrm{N}_{2} \mathrm{O}$ flux in a field previously planted with corn (Zea mays) in southern Rhode Island, USA. Plots were amended with $\left({ }^{15} \mathrm{NH}_{4}\right)_{2} \mathrm{SO}_{4}$ and either 0 (CTL) or $48 \mathrm{~L}$. terrestris $\mathrm{m}^{-2}$ (EW). The flux of $\mathrm{N}_{2} \mathrm{O},{ }^{15} \mathrm{~N}_{2} \mathrm{O}$ and ${ }^{15} \mathrm{~N}_{2}$ was measured over 28 days between October and November 2008. The EW treatment had a significantly higher flux of $\mathrm{N}_{2} \mathrm{O}$ and ${ }^{15} \mathrm{~N}_{2} \mathrm{O} 1-3$ days after ${ }^{15} \mathrm{NH}_{4}$ addition. No treatment effects were observed on ${ }^{15} \mathrm{~N}_{2}$ flux. The addition of earthworms significantly increased (Day 1) and decreased (Day 12) the mole fraction of $\mathrm{N}_{2} \mathrm{O}$ relative to the CTL. Our results suggest that anecic earthworm additions can increase $\mathrm{N}_{2} \mathrm{O}$ flux from inorganic fertilizer $\mathrm{N}$ amendments, but the effects appear to short-lived.
\end{abstract}

Keywords: Lumbricus terrestris; Anecic Earthworms; Fertilizer Nitrogen; Nitrous Oxide Flux; Denitrification

\section{Introduction}

Upland agricultural soils account for $\sim 28 \%$ of the global $\mathrm{N}_{2} \mathrm{O}$ budget [1]. Anecic earthworms play a key role in upland agroecosystems [2], where they translocate crop residues, accelerate decomposition and nutrient mineralization, increase inorganic $\mathrm{N}$, change the physical properties of soil (e.g. pore size distribution, water retention, gas diffusion), and alter the size, composition and activities of microbial and faunal communities. These effects overlap with known controls on $\mathrm{N}_{2} \mathrm{O}$ flux in soil [3], including availability of precursors, inhibitors, electron donors and acceptors, the size and spatial distribution of relevant microbial populations, and the establishment of conditions necessary for their activities.

Increasing the number of earthworms in agricultural soils is a key component of programs that promote soil quality and sustainability [4,5], such as reduced and conservation tillage. Conservation tillage practices were used on more than 109 million acres of farmland in the US in 2000 , with a three-fold increase in no-till acreage between 1990 and 2000 [6]. These practices are also increasingly being adopted in Europe [7] and Africa [8].
Adoption of farming practices that retain plant residues, minimize soil disturbance and rely more extensively on foodweb interactions for plant nutrition is expected to ameliorate the impact of agriculture on greenhouse gases $[9,10]$. However, the positive impact of these practices may be negated by unintended effects on $\mathrm{N}_{2} \mathrm{O}$ flux [9], some of which may be associated with larger earthworm population densities. The number of earthworms can increase 5 - 10 fold in no-till relative to plowed fields $[11,12]$, and no-till practices preferentially benefit anecic, deep-burrowing species like Lumbricus terrestris [12-14].

Recent reviews suggest that earthworms have varying effects on $\mathrm{N}_{2} \mathrm{O}$ flux in soil $[15,16]$. For example, Rizhiya et al. [17] reported that inoculation of soil mesocosms containing crop residues with Aporrectodea longa, an anecic earthworm, increased emissions of $\mathrm{N}_{2} \mathrm{O}$ nearly four-fold relative to uninoculated soil over the course of 90 days. In another soil mesocosm experiment, Bertora et al. [18] observed only an initial, transient increase in $\mathrm{N}_{2} \mathrm{O}$ flux for treatments inoculated with $A$. longa relative to an uninoculated control. More recently Evers et al. [19] reported that soil mesocosms with a high moisture content inoculated with $L$. terrestris at high population den- 
sities had significantly higher $\mathrm{N}_{2} \mathrm{O}$ emissions than uninoculated controls. Epigeic and endogeic earthworms have also been shown to increase $\mathrm{N}_{2} \mathrm{O}$ emissions in soil mesocosms [20]. The results of these studies point to the need for field-scale evaluation of the effects of earthworms on the flux of $\mathrm{N}_{2} \mathrm{O}$ from agricultural soils.

In a previous study we reported that inoculation of mesocosms with $L$. terrestris appeared to increase nitrogenous gas losses from ${ }^{15} \mathrm{~N}$-labeled corn litter [21]. In the present study we determined the effects of inoculation with $L$. terrestris on the flux of $\mathrm{N}_{2} \mathrm{O}$ in corn field plots amended with $\left({ }^{15} \mathrm{NH}_{4}\right)_{2} \mathrm{SO}_{4}$. The use of ${ }^{15} \mathrm{~N}$-labeled ammonium allowed us to examine the extent to which anecic earthworms affect production of nitrogenous gas emissions from a common inorganic fertilizer.

\section{Materials and Methods}

\subsection{Site Description}

Our experiment was conducted at a University of Rhode Island research farm in Kingston, Rhode Island, USA. The soil at the site is an Enfield silt loam (Coarse-silty over sandy or sandy-skeletal, mixed, active, mesic Typic Dystrudepts) [22]. The soil (top $10 \mathrm{~cm} ; \mathrm{n}=6$ ) had a pH of 5.9 and an organic matter content of $18.1 \mathrm{~g}^{\mathrm{kg}}{ }^{-1}$. Levels of extractable ammonium and nitrate were 9.9 and 4.2 $\mathrm{mg} \mathrm{N} \cdot \mathrm{kg}^{-1}$ soil, respectively. The field was used to grow corn using conventional management practices and the corn had been harvested prior to our experiment. The field had a mean $(n=6)$ earthworm population density of 44 individuals $\mathrm{m}^{-2}$, and an earthworm biomass of $26.8 \mathrm{~g}$ fresh weight $\mathrm{m}^{-2}$. No anecic earthworms were found in the area.

\subsection{Experimental Design}

Six square plots $\left(0.25 \mathrm{~m}^{2}\right)$ were established in a straight line, $1.0 \mathrm{~m}$ apart on-edge, parallel to a row. One of two earthworm addition rates was assigned randomly to each plot: 0 (CTL) or 48 earthworms $\mathrm{m}^{-2}$ (EW), with each rate replicated three times. An additional plot was used to record soil temperature. Every plot was surrounded by a fiberglass screen $(20 \mathrm{~cm}$ buried below the surface, $26 \mathrm{~cm}$ above) to prevent loss of corn litter, limit earthworm migration, and allow for unaltered hydrologic connections. After the screens were installed, $150 \mathrm{~g}\left(600 \mathrm{~g} \cdot \mathrm{m}^{-2}\right)$ of air-dried, aged corn leaf litter $(\mathrm{C} / \mathrm{N}=18.9)$ gathered from the experimental field (cut into $\sim 2.0 \mathrm{~cm}$ pieces) was applied to the plots on 30 September 2008. Plots were inoculated with adult anecic earthworms (L. terrestris; obtained from a commercial outlet) on 7 October 2008. The earthworms had a mean $(\mathrm{n}=10)$ fresh weight of $5.3 \pm$ $0.9 \mathrm{~g}$.

On 8 October 2008 the corn litter was removed quan- titatively from each plot and stored, and $572 \mathrm{mg}{ }^{15} \mathrm{~N} \cdot \mathrm{m}^{-2}$ (as $\left({ }^{15} \mathrm{NH}_{4}\right)_{2} \mathrm{SO}_{4} ; 60$ At.\%) was applied to each plot in $100 \mathrm{~mL}(\sim 0.04 \mathrm{~cm})$ of water using a pressurized dispersion apparatus that delivered the solution at a rate of 20 $\mathrm{mL} \cdot \mathrm{s}^{-1}$. This amount of water and application rate resulted in quick infiltration into the soil, preventing pooling and runoff. The corn litter was placed back on the plots after application of $\left({ }^{15} \mathrm{NH}_{4}\right)_{2} \mathrm{SO}_{4}$.

\subsection{Gas Sampling and Analysis}

A cylindrical plastic chamber (20-cm dia., 16-cm high) fitted with a rubber septum on the top was used to measure the flux of $\mathrm{N}_{2} \mathrm{O}$. At the time of sampling the chamber was placed randomly within the plot and pushed $\sim 2.5 \mathrm{~cm}$ into the soil. A sample of the gases within the chamber was obtained initially and within $30-45 \mathrm{~min}$ after chamber placement with a $20-\mathrm{mL}$ gas-tight syringe. The syringe was pumped three times to mix the gases in the headspace prior to sample collection, and the sample transferred immediately to a $15-\mathrm{mL}$ evacuated tube (Vacutainer $^{\mathbb{B}}$; BD, Franklin Lakes, NJ). The concentration of $\mathrm{N}_{2} \mathrm{O}$ and the ${ }^{15} \mathrm{~N}$ enrichment of ${ }^{15} \mathrm{~N}_{2} \mathrm{O}$ and ${ }^{15} \mathrm{~N}_{2}$ were determined at the Stable Isotope Facility, University of California, Davis, CA, USA. Isotope ratios were measured using a SerCon Cryoprep trace gas concentration system interfaced to a PDZ Europa 20 - 20 isotope ratio mass spectrometer (SerCon Ltd., Cheshire, UK). Gas fluxes were calculated as described by Mosier and Schimel [23]. The total mass of $\mathrm{N}_{2} \mathrm{O}-\mathrm{N},{ }^{15} \mathrm{~N}_{2} \mathrm{O}-{ }^{15} \mathrm{~N}$ and ${ }^{15} \mathrm{~N}_{2}-$ ${ }^{15} \mathrm{~N}$ emitted from the plots over the course of the 28-day experiment was estimated from the area under each curve.

\subsection{Additional Measurements}

Soil temperature was measured with a digital thermometer at a depth of $10 \mathrm{~cm}$ in a separate uninoculated plot treated in an identical manner as the other experimental plots. Soil $\mathrm{pH}, \mathrm{OM}$ and extractable $\mathrm{N}$ content, and the $\mathrm{C} / \mathrm{N}$ ratio of corn litter were determined as described in Savin et al. [24]. At the end of the experiment (28 days after addition of $\left({ }^{15} \mathrm{NH}_{4}\right)_{2} \mathrm{SO}_{4}$, the leaf litter was removed quantitatively from each plot and dried to a constant weight at $60^{\circ} \mathrm{C}$. The dried leaf litter was separated from soil using tweezers and the dry mass of litter recorded for each plot. Soil samples (top $10 \mathrm{~cm}$, one per plot) were obtained after litter removal.

\subsection{Statistical Analysis}

Student's $t$-test was used to examine treatment differences for gas and isotope data $(\mathrm{P}<0.05)$. A one-way analysis of variance was used to examine differences in mass of litter and soil properties. 


\section{Results}

At the end of the experiment the amount of litter ( $g$ dry weight $\mathrm{m}^{-2}$ ) remaining in both treatments was significantly lower relative to the initial amount, and was significantly lower in the EW than the CTL treatment, with mean (s.d.) values of $232 \pm 26$ and $395 \pm 19$ for the EW and CTL treatments, respectively. No significant differences were observed between initial and final levels of soil $\mathrm{NH}_{4}$ and $\mathrm{NO}_{3}$ for either treatment (data not shown).

Addition of earthworms significantly increased the flux of $\mathrm{N}_{2} \mathrm{O}$ relative to the CTL treatment 1 day after addition of $\left({ }^{15} \mathrm{NH}_{4}\right)_{2} \mathrm{SO}_{4}$ to the plots (Figure 1). No significant differences in flux were observed subsequently between EW and CTL treatments, and the lowest flux values for both treatments were observed between Day 12 and Day 15. The flux of $\mathrm{N}_{2} \mathrm{O}$ increased in both treatments from Day 15 until the end of the experiment, coinciding with a number of precipitation events that yielded
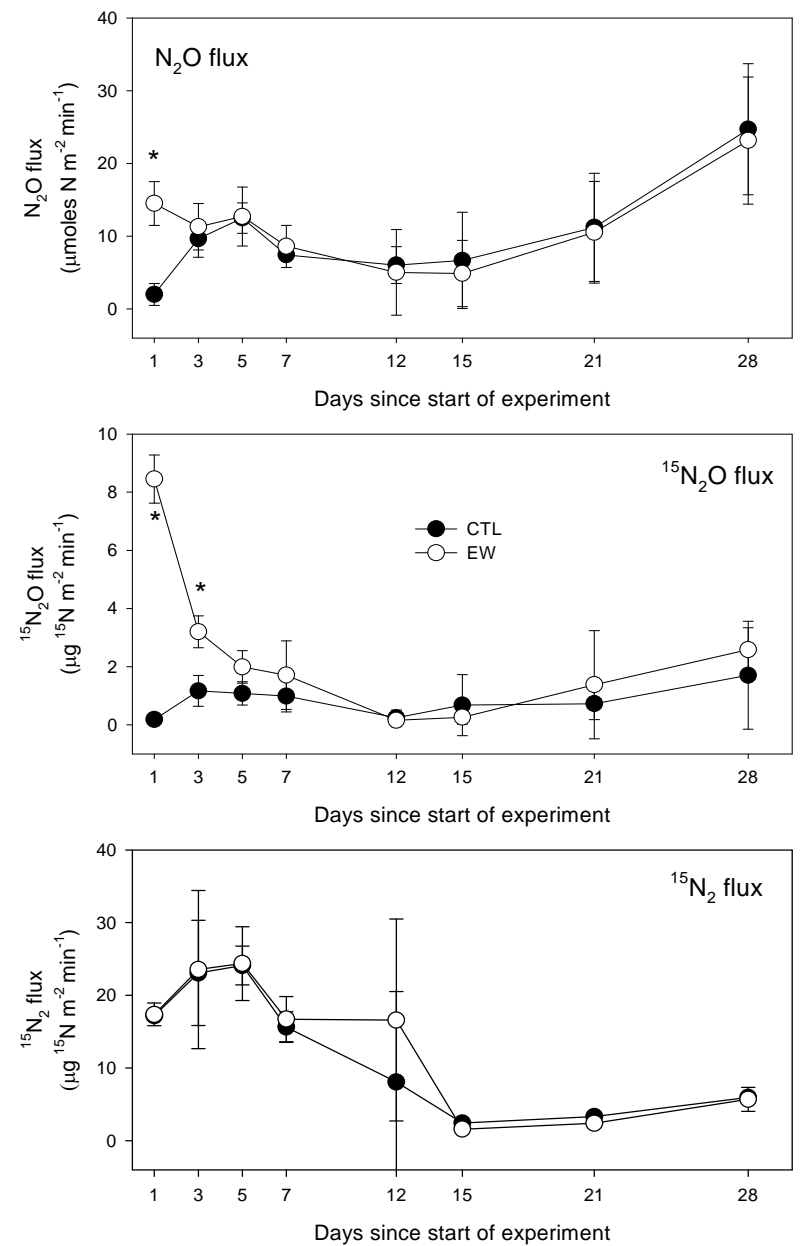

Figure 1. Flux of $\mathrm{N}_{2} \mathrm{O},{ }^{15} \mathrm{~N}_{2} \mathrm{O}$ and ${ }^{15} \mathrm{~N}_{2}$ as a function of time for field plots amended with 0 (CTL) or 48 Lumbricus terrestris $\mathrm{m}^{-2}(\mathrm{EW})$. Values are means $(\mathrm{n}=3)$; bars represent one standard deviation. $(*)$ indicates significant difference $(\mathbf{P}<0.05)$. a total of $\sim 3.5 \mathrm{~cm}$ of rain during the last 13 days of the experiment (Figure 2). No significant differences were observed in total mass of $\mathrm{N}_{2} \mathrm{O}-\mathrm{N}$ emitted over 28 days (Table 1).

The flux of ${ }^{15} \mathrm{~N}_{2} \mathrm{O}$ was significantly higher for the EW treatment on Day 1 and Day 3 (Figure 1). No significant differences were observed among treatments between Day 5 and Day 28, and the lowest flux was observed between Day 12 and Day 15. The ${ }^{15} \mathrm{~N}_{2} \mathrm{O}$ flux increased steadily in both treatments after Day 15 until the end of the experiment. The total amount of ${ }^{15} \mathrm{~N}$ emitted as ${ }^{15} \mathrm{~N}_{2} \mathrm{O}$ over 28 days was significantly higher for the EW than for the CTL treatment (Table 1). The yield of ${ }^{15} \mathrm{~N}_{2} \mathrm{O}$ from ${ }^{15} \mathrm{NH}_{4}$ initially added was $5.8 \%$ for CTL and $11.6 \%$ for the EW treatment (Table 1).

There were no significant differences in ${ }^{15} \mathrm{~N}_{2}$ flux between treatments on any sampling day (Figure 2). The flux was highest on Day 3, lowest on Day 15, and increased subsequently until the end of the experiment. There were no significant differences in the total amount of ${ }^{15} \mathrm{~N}$ emitted as ${ }^{15} \mathrm{~N}_{2}$ over 28 days (Table 1). The yield of ${ }^{15} \mathrm{~N}_{2}$ from ${ }^{15} \mathrm{NH}_{4}$ was $17.9 \%$ and $15.2 \%$ for the CTL and EW treatments, respectively (Table 1). The yield of ${ }^{15} \mathrm{~N}$-labeled gases was lowest for the CTL (23.7\%) and highest for the EW treatment $(26.8 \%)$.

Significant differences in the mole fraction of ${ }^{15} \mathrm{~N}_{2} \mathrm{O}$ between treatments were observed on Day 1 and Day 12 (Figure 3). On Day 1, the mole fraction in the EW treatment was 0.87 , with a value of 0.16 observed for the CTL treatment $(0.16)$. On Day 12 the highest mole fraction (0.56) was observed for the CTL treatment, whereas the EW treatment had a value of 0.18 .

\section{Discussion}

The dynamics of ${ }^{15} \mathrm{~N}_{2} \mathrm{O}$ and ${ }^{15} \mathrm{~N}_{2}$ production were generally similar for both treatments, suggesting a synchrony

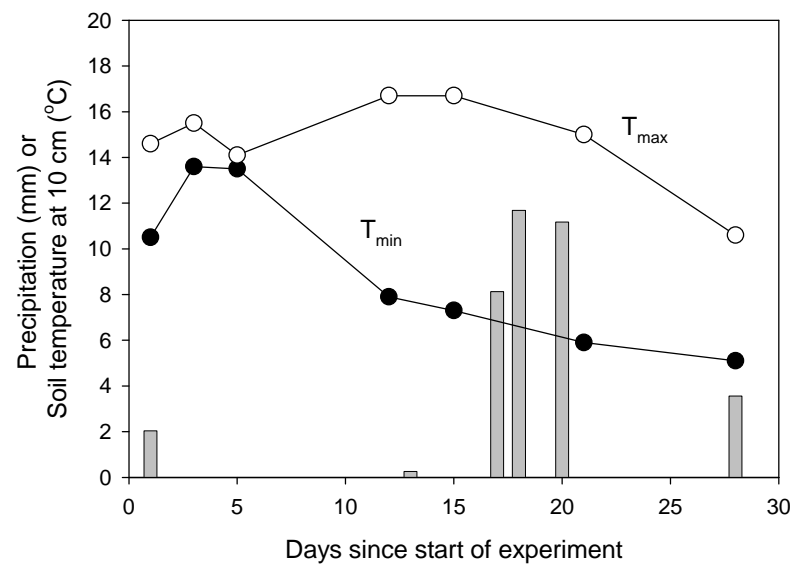

Figure 2. Precipitation and maximum and minimum soil temperature at a depth of $10 \mathrm{~cm}$ in field plots during the course of the experiment. 
Table 1. Total mass of $\mathrm{N}_{2} \mathrm{O}-\mathrm{N}, \mathrm{N}_{2} \mathrm{O}-{ }^{15} \mathrm{~N}$, and $\mathrm{N}_{2^{-}}{ }^{15} \mathrm{~N}$ over the course of 28 days, and yield of ${ }^{15} \mathrm{~N}_{2} \mathrm{O},{ }^{15} \mathrm{~N}_{2}$ and ${ }^{15} \mathrm{~N}_{2}$ gases from added ${ }^{15} \mathrm{NH}_{4}$ in uninoculated plots (CTL) and plots inoculated with $48 \mathrm{~L}$. terrestris $\mathrm{m}^{-2}(\mathrm{EW})$. Values in bold within a column were significantly different $(\mathrm{P}<\mathbf{0 . 0 5})$.

\begin{tabular}{ccccccc}
\hline Tmt & $\begin{array}{c}\text { Mass of } \mathrm{N}_{2} \mathrm{O}-\mathrm{N} \\
\left(\mathrm{g} \cdot \mathrm{m}^{-2}\right)\end{array}$ & $\begin{array}{c}\text { Mass of }{ }^{15} \mathrm{~N}_{\text {as }} \mathrm{N}_{2} \mathrm{O} \\
\left(\mathrm{mg} \cdot \mathrm{m}^{-2}\right)\end{array}$ & $\begin{array}{c}\text { Yield of }{ }^{15} \mathrm{~N}_{2} \mathrm{O} \\
(\%)\end{array}$ & $\begin{array}{c}\text { Mass of }{ }^{15} \mathrm{~N}^{-2} \mathrm{~N}_{2} \\
\left(\mathrm{mg} \cdot \mathrm{m}^{-2}\right)\end{array}$ & $\begin{array}{c}\text { Yield of }{ }^{15} \mathrm{~N}_{2} \\
(\%)\end{array}$ & $\begin{array}{c}\text { Yield of }{ }^{15} \mathrm{~N} \text { gases } \\
(\%)\end{array}$ \\
\hline CTL & $5.76 \pm 2.43$ & $\mathbf{3 2 . 9} \pm \mathbf{2 5 . 9}$ & 5.8 & 101.6 & 17.9 & 23.7 \\
EW & $5.72 \pm 2.56$ & $64.2 \pm 15.8$ & 11.6 & 113.3 & 15.2 & 26.8 \\
\hline
\end{tabular}

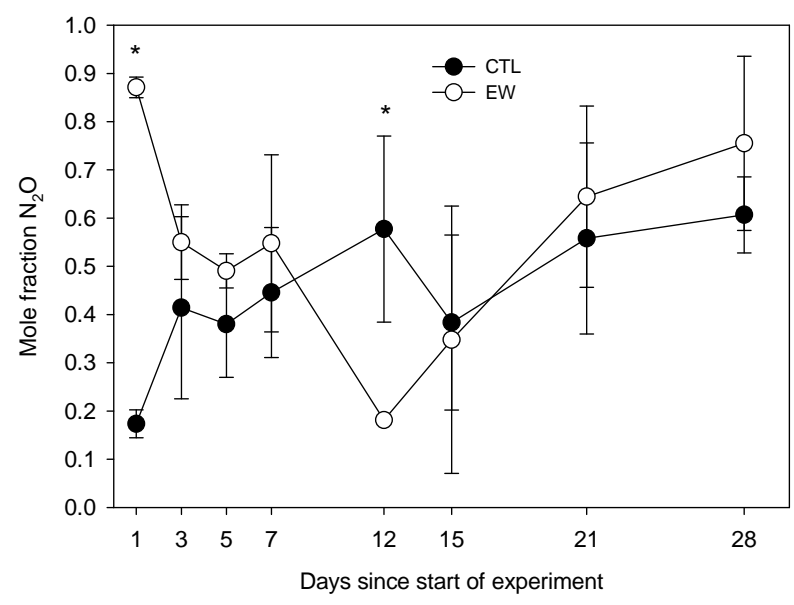

Figure 3. Mole fraction of ${ }^{15} \mathrm{~N}_{2} \mathrm{O}$ as a function of time for field plots amended with 0 (CTL) or 48 Lumbricus terrestris $\mathbf{m}^{-2}(\mathrm{EW})$. Values are means $(\mathrm{n}=3)$; bars represent one standard deviation. (*) indicates significant difference $(\mathrm{P}<$ 0.05).

driven by external factors common to all plots, such as soil moisture and temperature (Figure 2). In particular, the timing of precipitation events appeared to exert an important control on $\mathrm{N}_{2} \mathrm{O}$ flux. This is consistent with previous reports that $\mathrm{N}_{2} \mathrm{O}$ flux responds positively to increases in soil moisture [25].

The $\mathrm{N}_{2} \mathrm{O}$ flux values in the present study ranged from 0.23 to $5.7 \mu \mathrm{g} \mathrm{N}_{2} \mathrm{O}-\mathrm{N} \mathrm{m}^{-2} \cdot \mathrm{s}^{-1}$, higher than those reported by Molodovskaya et al. [26], who found average flux values in a corn field of $0.059 \mu \mathrm{g} \mathrm{N} \mathrm{N}_{2} \mathrm{O}-\mathrm{N} \mathrm{m}^{-2} \cdot \mathrm{s}^{-1}$, with a maximum flux of $0.76 \mu \mathrm{g} \mathrm{N} \mathrm{N}_{2} \mathrm{O}-\mathrm{N} \mathrm{m}^{-2} \cdot \mathrm{s}^{-1}$ observed during a spring thaw event. The fraction of available $\mathrm{N}$ converted to $\mathrm{N}_{2} \mathrm{O}$ for soils planted to grain crops has been reported by Tonitto et al. [27] to vary from less than 1 to about $4 \%$ on a seasonal scale, whereas our values ranged from $5.8 \%$ to $11.6 \%$. The high values for flux and greater fraction of added $\mathrm{N}$ converted to $\mathrm{N}_{2} \mathrm{O}$ in our study may be due to the high soil moisture content and presence of high amounts of plant litter, both of which promote $\mathrm{N}_{2} \mathrm{O}$ production in agricultural soils [3]. The absence of a plant sink for $\mathrm{NO}_{3}$ may also have contributed to higher than expected flux values. Relative losses of ${ }^{15} \mathrm{~N}$ in gaseous forms in the present study for the EW treatment (Table 1) were comparable to those estimated by Amador and Görres [21] for mesocosms inoculated with earthworms at a rate of $127 \mathrm{~m}^{-2}(16.8 \%$ to $39.8 \%)$, but losses in the CTL treatment were higher than for mesocosms without earthworms in that study (1.9\% to $7.4 \%)$. The differences are likely due to differences in soil moisture and temperature that favored denitrification under field conditions.

The effects of earthworm additions on $\mathrm{N}_{2} \mathrm{O}$ flux under field conditions in the present study are in general agreement with those observed by others. For example, Borken et al. [28] reported a 57\% increase in $\mathrm{N}_{2} \mathrm{O}$ emissions from field mesocosms containing forest soil and inoculated with $L$. terrestris at a population density of 113 individuals $\mathrm{m}^{-2}$. Evers et al. [19] observed that inoculation of mesocosms containing a sandy loam from a forested area with $L$. terrestris at population densities greater than $300 \mathrm{~m}^{-2}$ had $\mathrm{N}_{2} \mathrm{O}$ emission rates that were significantly higher than uninoculated mesocosms. Furthermore, the effects of $L$. terrestris depended on soil moisture, with maximum values at $35 \%$. However, the effects of $L$. terrestris were not observed when inoculated at densities representative of field values (90 - 270 $\mathrm{m}^{-2}$ ). The addition of an anecic earthworm (Aporrectodea longa) in soil mesocosms with a high moisture content at a population density of $100 \mathrm{~m}^{-2}$ significantly increased the flux of $\mathrm{N}_{2} \mathrm{O}$ relative to soil without earthworms over the first 12 days of incubation, but the flux was significantly lower between days 44 and 62 in the earthworm treatment [18]. Rizhiya et al. [17] observed that additions of $A$. longa $\left(\sim 100 \mathrm{~m}^{-2}\right)$ to soil mesocosms containing grass residues significantly increased $\mathrm{N}_{2} \mathrm{O}$ flux relative to a control without earthworms. They suggested that the role of earthworms consisted of mixing residues into the soil, switching residue decomposition from aerobic to anaerobic, and from low denitrification to high denitrification and $\mathrm{N}_{2} \mathrm{O}$ production. By contrast, in a field study of the effects of anecic earthworm additions (L. terrestris and A. longa) on $\mathrm{N}_{2} \mathrm{O}$ flux during the growing season in an unfertilized cornfield, Speratti and Whalen [29] were unable to conclude that earthworms affected $\mathrm{N}_{2} \mathrm{O}$ flux. Although they observed generally higher $\mathrm{N}_{2} \mathrm{O}$ fluxes in enclosures amended with earthworms, poor survival of introduced earthworms and seasonal variability yielded flux values that were not significantly different [29].

Direct production of $\mathrm{N}_{2} \mathrm{O}$ by earthworms has been re- 
ported [30,31], but the flux is generally very low compared to total flux [18]. The positive effects of earthworms on denitrification are generally attributed to indirect mechanisms [26,27], including increased soil moisture in burrow soil and increased availability of organic carbon through translocation and greater physical contact of plant detritus with soil. Earthworms have also been shown to increase rates of nitrification in soil [26].

The effects of earthworm amendment were most apparent at the outset of the experiment, with significant differences disappearing after 5 days. The short time frame and dynamics of the effects suggest that these may be associated with activities such as burrowing, which took place within a day after inoculation. Van den Heuvel et al. [32] observed that soil disturbance resulted in considerably higher $\mathrm{N}_{2} \mathrm{O}$ emissions from soils in a riparian area, an effect they attributed to increased diffusion of $\mathrm{O}_{2}$. Denitrifiers decrease reduction of $\mathrm{N}_{2} \mathrm{O}$ to $\mathrm{N}_{2}$ as $\mathrm{O}_{2}$ levels increase [33]. This may explain the initial increase in $\mathrm{N}_{2} \mathrm{O}$ flux and higher $\mathrm{N}_{2} \mathrm{O}$ mole fraction in the EW treatment.

The presence of earthworms resulted in a significant increase (Day 1) and decrease (Day 12) in the mole fraction of ${ }^{15} \mathrm{~N}_{2} \mathrm{O}$ relative to the CTL (Figure 3). Firestone et al. [3] have shown that the mole fraction of $\mathrm{N}_{2} \mathrm{O}$ is a function of a number of variables, including soil $\mathrm{pH}$, concentration of $\mathrm{NO}_{3}$ and $\mathrm{O}_{2}$, and time under anaerobiosis. Positive effects of earthworm additions on mole fraction of ${ }^{15} \mathrm{~N}_{2} \mathrm{O}$ may be due to higher concentrations of $\mathrm{NO}_{3}$ in earthworm burrows and casts [27,34], possibly as a result of increased $\mathrm{O}_{2}$ diffusion into soil [35]. By contrast, greater retention of moisture (and consequently lower $\mathrm{O}_{2}$ concentration) in casts and burrow soil due to shifts in pore size distribution [36] relative to bulk soil may have resulted in significantly lower mole fraction of ${ }^{15} \mathrm{~N}_{2} \mathrm{O}$ on Day 12.

\section{Conclusion}

We have shown that addition of L. terrestris to an agricultural soil at a rate of 48 earthworms $\mathrm{m}^{-2}$ significantly increased the flux of $\mathrm{N}_{2} \mathrm{O}$ and ${ }^{15} \mathrm{~N}_{2} \mathrm{O}$ in the early stages of the 28-day experimental period, as well as the total mass of ${ }^{15} \mathrm{~N}_{2} \mathrm{O}-\mathrm{N}$ emitted relative to an uninoculated control. Earthworms had no significant effect on the flux of ${ }^{15} \mathrm{~N}_{2}$. Our results need to be interpreted with caution, given the short duration of the experiment and the fact that it was conducted at the end of the growing seasonwhen temperature, moisture and plant detritus were likely optimal for earthworm activity and $\mathrm{N}_{2} \mathrm{O}$ emissions. As such, our data may represent an upper limit for effects of $L$. terrestris on ${ }^{15} \mathrm{~N}_{2} \mathrm{O}$ flux. Nevertheless, our results suggest that $L$. terrestris can enhance $\mathrm{N}_{2} \mathrm{O}$ emissions from a corn field temporarily. These results point to a need for better understanding of the mechanisms by which anecic earthworms affect trace gas fluxes as we move towards more sustainable, foodweb-based management of nutrients in agroecosystems.

\section{Acknowledgements}

This research was funded by an grant-in-aid from the University of Rhode Island's Provost's Office to E.J. Avizinis, by a grant from the USDA-AFRI program to J.A. Amador, and by private funds of the authors. This is contribution no. 5327 from the Rhode Island Agricultural Experiment Station.

\section{REFERENCES}

[1] J. P. Schimel and E. A. Holland, "Global Gases," In: J. J. Fuhrman, D. M. Sylvia, P. G. Hartel and D. A. Zuberer, Eds., Principles and Applications of Soil Microbiology, 2nd Edition, Pearson-Prentice Hall, Upper Saddle River, 2005, pp. 491-509.

[2] C. A. Edwards, "The Importance of Earthworms as Key Representatives of the Soil Fauna," In: C. A. Edwards, Ed., Earthworm Ecology, 2nd Edition, CRC Press, Boca Raton, 2004, pp. 3-11. doi:10.1201/9781420039719.pt1

[3] M. K. Firestone, R. B. Firestone and J. M. Tiedje, "Nitrous Oxide from Soil Denitrification: Factors Controlling Its Biological Production," Science, Vol. 208, 1980, pp. 749-751. doi:10.1126/science.208.4445.749

[4] A. J. Tugel and A. M. Lewandowski, "Soil Biology Primer,” NRCS Soil Quality Institute, Ames, 1999.

[5] FAO (Food and Agriculture Organization of the United Nations), "Manual on Integrated Soil Management and Conservation Practices," No. 8, Rome, 2000.

[6] C. Sandretto, "Conservation Tillage Firmly Planted in U.S. Agriculture," Agricultural Outlook: Economic Research Service-USDA, 2001, pp. 5-6.

[7] J. M. Holland, "The Environmental Consequences of Adopting Conservation Tillage in Europe: Reviewing the Evidence," Agriculture, Ecosystems \& Environment, Vol. 103, No. 1, 2004, pp. 1-25. doi:10.1016/j.agee.2003.12.018

[8] R. Fowler and J. Rockstrom, "Conservation Tillage for Sustainable Agriculture: An Agrarian Revolution Gathers Momentum in Africa," Soil and Tillage Research, Vol. 61, No. 1-2, 2001, pp. 93-107. doi:10.1016/S0167-1987(01)00181-7

[9] E. G. Gregorich, P. Rochette, A. J. VandenBygaart and D. A. Angers, "Greenhouse Gas Contributions of Agricultural Soils and Potential Mitigation Practices in Eastern Canada," Soil and Tillage Research, Vol. 83, No. 1, 2005, pp. 53-72. doi:10.1016/j.still.2005.02.009

[10] R. Lal, J. M. Kimble, R. F. Follett and C. B. Cole, "The Potential of U.S. Cropland to Sequester Carbon and Mitigate the Greenhouse Effect," CRC Press, Boca Raton, 1998.

[11] C. A. Edwards and J.R. Lofty, "The Effect of Direct 
Drilling and Minimal Cultivation on Earthworm Populations," Journal of Applied Ecology, Vol. 19, 1982, pp. 723-734. doi: $10.2307 / 2403277$

[12] W. Ehlers, "Observations on Earthworm Channels and Infiltration on Tilled and Untilled Loess Soil," Soil Science, Vol. 119, 1975, pp. 242-249.

doi:10.1097/00010694-197503000-00010

[13] W. M. Edwards, M. J. Shipitalo, L. B. Owens and L. D. Norton, "Effect of Lumbricus terrestris L. Burrows on Hydrology of Continuous No-Till Corn Fields," Geoderma, Vol. 46, No. 1-3, 1990, pp. 73-84. doi:10.1016/0016-7061(90)90008-W

[14] V. Nuutinen, "Earthworm Community Response to Tillage and Residue Management on Different Soil Types in Southern Finland," Soil and Tillage Research, Vol. 23, No. 3, 1992, pp. 221-239. doi:10.1016/0167-1987(92)90102-H

[15] C. A. Edwards, "Can Earthworms Harm the Planet?" BioCycle, Vol. 49, 2008, p. 53.

[16] J. G. Ehrenfeld, "Ecosystem Consequences of Biological Invasions," Annual Review of Ecology, Evolution, and Systematics, Vol. 41, 2010, pp. 59-80. doi:10.1146/annurev-ecolsys-102209-144650

[17] E. Rizhiya, C. Bertora, P. C. J. van Vliet, P. J. Kuikman, J. H. Faber and J. W. van Groenigen, "Earthworm Activity as a Determinant for $\mathrm{N}_{2} \mathrm{O}$ Emission From Crop Residue," Soil Biology \& Biochemistry, Vol. 39, No. 8, 2007, pp. 2058-2069. doi:10.1016/j.soilbio.2007.03.008

[18] C. Bertora, P. C. J. van Vliet, E. W. J. Hummelink and J. W. van Groenigen, "Do Earthworms Increase $\mathrm{N}_{2} \mathrm{O}$ Emissions in Ploughed Grassland?" Soil Biology \& Biochemistry, Vol. 39, No. 2, 2007, pp. 632-640. doi:10.1016/j.soilbio.2006.09.015

[19] A. K. Evers, T. A. Demers, A. M. Gordon and N. V. Thevathasan, "The Effects of Earthworm (Lumbricus terrestris L.) Population Density and Soil Water Content Interactions on Nitrous Oxide Emissions from Agri- cultural Soils," Applied and Environmental Soil Science, Vol. 2010, 2010, Article ID: 737096, 9 p. doi:10.1155/2010/737096

[20] G. Giannopoulos, M. M. Pulleman and J. W. Van Groenigen, "Interactions netween Residue Placement and Earthworm Ecological Strategy Affect Aggregate Turnover and $\mathrm{N}_{2} \mathrm{O}$ Dynamics in Agricultural Soil," Soil Biology \& Biochemistry, Vol. 42, No. 4, 2010, pp. 618-625. doi:10.1016/i.soilbio.2009.12.015

[21] J. A. Amador and J. H. Görres, "Role of the Anecic Earthworm Lumbricus terrestris L. in the Distribution of Plant Residue Nitrogen in a Corn (Zea mays)-Soil System," Applied Soil Ecology, Vol. 30, No. 3, 2005, pp. 203-214. doi:10.1016/j.apsoil.2005.02.011

[22] Soil Survey Staff, "Official Soil Series Descriptions." http://soils.usda.gov/technical/classification/osd/index.html

[23] A. R. Mosier and D. S. Schimel, "Nitrification and Denitrification," In: R. Knowles and T. H. Blackburn, Eds., Nitrogen Isotope Techniques, Academic Press, San Diego, 1993, pp. 181-208.

[24] M. C. Savin, J. H. Görres, D. A. Neher and J. A. Amador,
"Biogeophysical Factors Influencing Soil Respiration and Mineral Nitrogen Content in an Old Field Soil," Soil Biology \& Biochemistry, Vol. 33, No. 4-5, 2001, pp. 429438. doi:10.1016/S0038-0717(00)00182-6

[25] P. M. Groffman and J. M. Tiedje, "Denitrification Hysteresis during Wetting and Drying Cycles in Soil," Soil Science Society of America Journal, Vol. 52, 1988, pp. 1626-1629. doi:10.2136/sssaj 1988.03615995005200060022x

[26] T. B. Parkin and E. C. Berry, "Microbial Nitrogen Transformations in Earthworm Burrows," Soil Biology \& Biochemistry, Vol. 31, No. 13, 1999, pp. 1765-1771. doi:10.1016/S0038-0717(99)00085-1

[27] T. B. Parkin and E. C. Berry, "Nitrogen Transformations Associated with Earthworm Casts," Soil Biology \& Biochemistry, Vol. 26, No. 9, 1994, pp. 1233-1238. doi:10.1016/0038-0717(94)90148-1

[28] W. Borken, S. Gründel and F. Beese, "Potential Contribution of Lumbricus terrestris L. to Carbon Dioxide, Methane and Nitrous Oxide Fluxes from a Forest Soil," Biology and Fertility of Soils, Vol. 32, No. 2, 2000, pp. 142-148. doi:10.1007/s003740000228

[29] A. B. Speratti and J. K. Whalen, "Carbon Dioxide and Nitrous Oxide Fluxes from Soil as Influenced by Anecic and Endogeic Earthworms," Applied Soil Ecology, Vol. 38 , No. 1,2008 , pp. 27-33. doi:10.1016/j.apsoil.2007.08.009

[30] P. K. Wust, M. A. Horn, G. Henderson, P. H. Janssen, B. H. A. Rehm and H. L. Drake, "Gut-Associated Denitrification and in Vivo Emission of Nitrous Oxide by the Earthworm Families Megascolecidae and Lumbricidae in New Zealand," Applied and Environmental Microbiology, Vol. 75, No. 11, 2009, pp. 3430-3436. doi:10.1128/AEM.00304-09

[31] H. L. Drake and M. A. Horn, "Earthworms as a Transient Heaven for Terrestrial Denitrifying Microbes: A Review," Engineering in Life Sciences, Vol. 6, No. 3, 2006, pp. 261-265. doi:10.1002/elsc.200620126

[32] R. N. van den Heuvel, M. M. Hefting, N. C. G. Tan, M. S. M. Jetten and J. T. A. Verhoeven, " $\mathrm{N}_{2} \mathrm{O}$ Emission Hotspots at Different Spatial Scales and Governing Factors for Small Scale Hotspots," Science of the Total Environment, Vol. 407, No. 7, 2009, pp. 2325-2332. doi:10.1016/j.scitotenv.2008.11.010

[33] M. A. Cavigelli and G. P. Robertson, "Role of Denitrifier Diversity in Rates of Nitrous Oxide Consumption in a Terrestrial Ecosystem," Soil Biology \& Biochemistry, Vol. 33, No. 3, 2001, pp. 297-310. doi:10.1016/S0038-0717(00)00141-3

[34] J. H. Gorres, M. C. Savin and J. A. Amador, "Dynamics of Carbon and Nitrogen Mineralization, Microbial Biomass, and Nematode Abundance Within and Outside the Burrow Walls of Anecic Earthworms (Lumbricus terrestris)," Soil Science, Vol. 162, 1997, pp. 666-671. doi:10.1097/00010694-199709000-00008

[35] A. Kretzschmar and P. Monestiez, "Physical Control of Soil Biological Activity Due to Endogeic Earthworm Behavior," Soil Biology \& Biochemistry, Vol. 24, No. 12, 1992, pp. 1609-1614. 
doi:10.1016/0038-0717(92)90158-T

[36] J. H. Görres, M. C. Savin and J. A. Amador, "Soil Micropore Structure and Carbon Mineralization in Burrows and Casts of an Anecic Earthworm (Lumbricus terre- stris)," Soil Biology \& Biochemistry, Vol. 33, No. 14, 2001, pp. 1881-1887.

doi:10.1016/S0038-0717(01)00068-2 